\title{
LncRNA KCNQIOTI Promotes Proliferation, Invasion and Metastasis of Prostate Cancer by Regulating miR-2II-5p/CHI3LI Pathway
}

This article was published in the following Dove Press journal: OncoTargets and Therapy

\author{
Hailong Hao' \\ Huiqing Chen' \\ Liwu $\mathrm{Xie}^{2}$ \\ Hongyu Liu' \\ Dongwen Wang ${ }^{3}$
}

'Department of Urology, Shanxi Cancer Hospital, Affiliated Cancer Hospital of Shanxi Medical University, Taiyuan,

Shanxi, People's Republic of China; ${ }^{2}$ Department of Pathology, Shanxi Cancer Hospital, Affiliated Cancer Hospital of Shanxi Medical University, Taiyuan, Shanxi, People's Republic of China; ${ }^{3}$ National Cancer Center/National Clinical Research Center for Cancer/ Cancer Hospital \& Shenzhen Hospital, Chinese Academy of Medical Sciences and Peking Union Medical College, Shenzhen, People's Republic of China

Correspondence: Dongwen Wang Email urology2007@I26.com
Background: Bone metastasis after failure of castration therapy is the main reason of death in patients with prostate cancer (PCa). Therefore, full awareness of the metastasis mechanism of PCa and discovery of new therapeutic targets are necessary. Studies showed that lncRNA was involved in the development of cancer. However, its potential role and molecular mechanism in PCa metastasis are still unclear. YKL-40 is an 18 glycosyl hydrolase family protein encoded by $\mathrm{CHI} 3 \mathrm{~L} 1$, which is involved in the invasion and metastasis of various tumors. A previous study of the authors found that YKL-40 was related to the invasion and metastasis of PCa cells. However, the cause of its abnormal expression in PCa remains unclear. The present study explored the role of lncRNA KCNQ1OT1/miR-211-5p/CHI3L1 regulatory axis in the proliferation, invasion, and metastasis of $\mathrm{PCa}$.

Methods: RT-PCR and Western blot were used to measure the expression profiles of KCNQ1OT1 and YKL. CCK-8 and Transwell assays were used to examine their effects on cell proliferation and migration. Double luciferase reporter assay was used to verify the interactions between miR-211-5p and CHI3L1 3'-UTR.

Results: KCNQ1OT1 expression was upregulated in PCa tissues and cells. Downregulating this expression inhibited PCa cell invasion, proliferation, and metastasis. KCNQ1OT1 bound miR-211-5p competitively, and miR-211-5p targeted CHI3L1 3'-UTR. miR-211-5p expression was downregulated, whereas CHI3L1 (YKL-40) expression was upregulated. miR-211$5 p$ levels were negatively correlated with KCNQ1OT1 expression and CHI3L1 mRNA. The decrease in YKL-40 expression in PCa cells induced by the downregulation of KCNQ1OT1 expression could be offset by miR-211-5p inhibitor transfection.

Conclusion: This study showed that lncRNA KCNQ1OT1, as a ceRNA, upregulated CHI3L1 and promoted PCa progression through competitive binding to miR-211-5p.

Keywords: prostatic cancer, PCa, lncRNA KCNQ1OT1, miR-211-5p, CHI3L1, competing endogenous RNA

\section{Introduction}

Prostate cancer (PCa) is a common malignant tumor in men. ${ }^{1}$ Approximately $80 \%$ of newly diagnosed PCa were localized and $20 \%$ were advanced or metastatic. The overall survival rate (OS) of local PCa is high. However, the survival rate of advanced and metastatic cases is significantly reduced, and the 5-year OS is only less than $30 \%{ }^{2}$ Androgen deprivation therapy (ADT) by drug or surgical castration has been the main treatment for metastatic PCa. However, patients ultimately develop resistance to ADT. Those with castration-resistant prostate cancer 
(CRPC) have rapid disease metastasis and usually die within 2-4 years. ${ }^{3}$ Therefore, an enhanced understanding of the metastasis mechanism of PCa could help treat it, especially CRPC.

CHI3L1 encodes YKL-40 protein, a member of the 18 glycosylhydrolase family. This protein is important for the proliferation, survival, and invasion of cancer cells. YKL40 could regulate cell matrix interaction, and it is involved in regulating extracellular matrix production. ${ }^{4}$ Previous reports showed that YKL-40 serum level was increased in patients with colorectal cancer, breast cancer, ovarian cancer, lung cancer, and $\mathrm{PCa}^{5-9}$ In breast cancer, YKL-40 could promote the synthesis and secretion of MMP-9, thus promoting breast cancer metastasis. ${ }^{10}$ A previous study of the authors showed that YKL-40 could promote the invasion and metastasis of PCa cells by regulating the epithelial-mesenchymal transition (EMT). ${ }^{11}$ However, the molecular mechanism of increased YKL-40 expression in $\mathrm{PCa}$ is still unclear.

Long-chain noncoding RNAs (lncRNAs) have attracted increasing attention as a kind of key regulatory molecule. Some IncRNAs regulate gene expression by recruiting transcriptional regulatory complexes and the binding sites of proximal (cis) or distal (trans) genomes, ${ }^{12}$ while others could be used as a scaffold or bait to assist with protein-lncRNA interaction. ${ }^{13}$ The abnormal expression of lncRNAs has been found in almost all tumors, and lncRNAs may be important for regulating the proliferation, drug resistance, and metastasis. ${ }^{14-16}$ For example, differentiation antagonizing non-protein coding RNA induces lymph node metastasis and proliferation in bladder cancer via a leucine-rich pentatricopeptide repeat containing-mediated mRNA stabilization mechanism. ${ }^{17}$ LncRNA-LBCS functions as a novel AR translational regulator that suppresses the castration resistance of $\mathrm{PCa}$ by interacting with hnRNPK. ${ }^{18}$ LncRNA SChLAP1 overexpression has been found in $\mathrm{PCa}$; it promotes the invasiveness of PCa by antagonizing the SWI/SNF chromatin modification complex. ${ }^{19}$ LncRNA HOTAIR promoted androgen-independent AR activity. ${ }^{20}$

Some studies showed that IncRNA KCNQ1OT1 played an important role in many biological processes, including stem cell differentiation, cell proliferation, and cancer progression. ${ }^{21-23}$ In colon cancer, lncRNA KCNQ1OT1 promoted chemoresistance by sponging miR-34a, thus upregulating Atg4B expression and enhancing protective autophagy. ${ }^{24}$ In acute myeloid leukemia, lncRNA KCNQ1OT1 controlled the proliferation, differentiation, and apoptosis in AML cells by acting as a competing endogenous RNA (ceRNA) for miR-326 to regulate c-Myc expression. ${ }^{25}$ In PCa, lncRNA KCNQ1OT1 sponged miR-15a to promote the immune evasion and malignant progression of PCa by upregulating PD-L1. ${ }^{26}$ In tongue cancer, IncRNA KCNQ1OT1 sponged miR-211$5 \mathrm{p} .^{22}$ Bioinformatic prediction revealed targeted binding sites between lncRNA KCNQ1OT1 and miR-211-5p and between miR-211-5p and CHI3L1 3'-UTR. Another previous study confirmed that $\mathrm{CHI} 3 \mathrm{~L} 1 / \mathrm{YKL}-40$ promoted the invasion and metastasis of PCa. ${ }^{11}$ MiR-211-5p acts as a tumor suppressor gene in various types of cancer. For example, miR-211-5p suppressed the metastatic behavior in renal cancer by targeting SNAI1. ${ }^{27}$ In hepatocellular carcinoma, miR-211-5p played a suppressing role in metastasis by targeting ZEB2. ${ }^{28}$ Therefore, lncRNA KCNQ1OT1 may act as a ceRNA to inhibit miR-211-5p, upregulate $\mathrm{CHI} 3 \mathrm{~L} 1$ expression, and promote the invasion and metastasis of $\mathrm{PCa}$.

In this study, two PCa cell lines DU145 and LNCaP were used, and the functional significance of the KCNQ1OT1/miR-211-5p/CHI3L1 axis on malignant behavior was examined to verify whether this regulatory axis may function and contribute to the malignant phenotypes of PCa. The results revealed that KCNQ1OT1 sponged miR-211-5p and subsequently upregulated CHI3L1, which promoted the malignant progression of PCa.

\section{Materials and Methods Subjects}

From February 2017 to December 2019, 30 cases of PCa tissues and their paracancerous tissues were taken from the Department of Urology, Shanxi Cancer Hospital. They were frozen in liquid nitrogen tank for subsequent nucleic acid extraction.

\section{Ethical Statement}

This study was conducted in accordance with the Declaration of Helsinki (as revised in 2013). All subjects signed the informed consent form.

\section{Cells}

Cells were cultured at $37{ }^{\circ} \mathrm{C}$ and $5 \% \mathrm{CO}_{2}$. MiR-211-5p mimic, miR-211-5p inhibitor, miR-NC, inhibitor $\mathrm{NC}$, KCNQ1OT1 siRNA, CHI3L1 siRNA, and si-NC were purchased from GenePharma (Shanghai, China). They were 
transfected into DU145 and LNCaP cells. Lipofectamine 3000 kit (ThermoFisher Scientific) was used for transfection in accordance with the manual. The cells were divided into control, si-NC, si-KCNQ1OT1, si-CHI3L1, miR-NC, miR211-5p mimic, si-KCNQ1OT1 + inhibitor NC, and siKCNQ1OT1 + miR-211-5p inhibitor groups.

\section{Rt-Pcr}

The total RNA of cells was extracted using a TRIzol reagent in accordance with the instructions. The purity and content of RNA were determined using a NanoDrop1000 spectrophotometer (ThermoFisher Scientific). A miScript II RT kit (Qiagen) was used for reverse transcription in accordance with the manual. MiR-211-5p mRNA expression was detected using Taqman specific PCR primers (Assay \# 002285) and a miScript PCR Kit (Qiagen) following the instructions of the manufacturers. The thermocycler conditions were $95^{\circ} \mathrm{C}$ for $10 \mathrm{~min}, 40$ cycles of $95^{\circ} \mathrm{C}$ for $12 \mathrm{~s}$, and $60{ }^{\circ} \mathrm{C}$ for 40 s. U6 and GAPDH were used as internal controls. Quantification was performed using the $2^{-\Delta \Delta} \mathrm{Ct}$ method. The primer sequences are listed in Table 1.

\section{Cell Viability Test}

Cell Counting Kit-8 (CCK-8, Beyotime, Shanghai, China) was used to analyze cell viability. It contains WST-8, which was reduced to formazan by dehydrogenase in the mitochondria under the action of 1-methoxy PMS, and the number of formazan was proportional to the number of living cells. The cells were collected and cultured in a 96-well plate $(2000$ cells/well) with a humidified incubator at $37^{\circ} \mathrm{C}$ and $5 \% \mathrm{CO}_{2}$ overnight. Then, $10 \mu \mathrm{L}$ of CCK-8 solution was added into each well. The $\mathrm{OD}_{450}$ value was detected using a plate reader every day to evaluate the cell viability at days $1-5$. The cells in each group were detected with six repeated wells.

\section{Matrigel Invasion and Transwell Migration Assays}

The cells were collected and diluted with a serum-free medium. They were inoculated with or without Matrigel 24 well Transwell filters. The lower chamber was added with $10 \%$ FBS and cultured for $12 \mathrm{~h}$. The cells were fixed and stained by crystal violet to count the cell number penetrating the membrane by using the microscope.

\section{Double Luciferase Reporter Gene Analysis}

Wild wt-pGL3-KCNQ1OT1 and mutant mut-pGL3KCNQ1OT1 plasmids were constructed on the basis of the prediction to detect the targeting effect of KCNQ1OT1 and miR-211-5p. KCNQ1OT1 luciferase reporter gene plasmids miR-211-5p and Renilla luciferase were co-transfected with HEK293 cells, and they were split using dual luciferase assay following the instructions after culture for $48 \mathrm{~h}$. The results were analyzed using a Panomics luminometer. They were homogenized via sea renin fluorescence.

Wild-type and mutant CHI3L1 3'-UTR luciferase reporter gene plasmids wt-pGL3-CHI3L1 and mut-pGL3CHI3L1 were constructed to analyze the action between miR-211-5p and CHI3L1 3'-UTR. MiR-211-5p and Renilla luciferase were co-transfected with HEK293 cells. The analysis conducted was the same as the above method.

\section{RNA Immunoprecipitation (RIP)}

RIP experiment was conducted using the EZMagna RIP kit. DU145 cells were harvested and lysed when they reached $80-90 \%$ of confluency. Then, the cell lysate (100 $\mu \mathrm{L})$ was incubated with anti-Ago 2 antibody bound magnetic beads, normal mouse IgG (negative control), or antiSNRNP70. Subsequently, they were incubated at $55^{\circ} \mathrm{C}$ for $30 \mathrm{~min}$ to remove the protein by using proteinase K. RNA was purified using the RNeasy Micro Kit (Qiagen, Dusseldorf, Germany). The content and purity of RNA were detected using the NanoDrop 1000 spectrophotometer (ThermoFisher Scientific).

\section{Western Blot}

Cells in different groups were harvested and lysed with a lysis solution. They were centrifuged at $4{ }^{\circ} \mathrm{C}(10,000 \mathrm{rpm})$ for 5 min, and the supernatant was collected. Proteins were then extracted. Their concentration was determined using BCA.

Table I Primers Used in the Study

\begin{tabular}{|l|l|l|}
\hline Gene & Forward Primer $\left(\mathbf{5}^{\prime} \mathbf{-} \mathbf{3}^{\prime} \mathbf{)}\right.$ & Reverse Primer $\left(\mathbf{5}^{\prime} \mathbf{-} \mathbf{3} \mathbf{)}\right.$ \\
\hline KCNQIOTI & ACTCACTCACTCACTCACT & CTGGCTCCTTCTATCACATT \\
CHI3LI & GTGAAGGCGTCTCAAACAGG & GAAGCGGTCAAGGGCATCT \\
GAPDH & GCTCTCTGCTCCTCCTGTTC & ACGACCAAATCCGTTGACTC \\
\hline
\end{tabular}


The proteins $(50 \mu \mathrm{g} / \mathrm{lane})$ were separated with $12 \%$ SDSPAGE, and then they were transferred to a membrane. The PVDF membrane was washed and blocked by a buffer. AntiYKL-40/CHI3L1 antibody (1:1000, Abcam, ab255297) and anti- $\beta$-actin antibody (1:2000, Abcam, ab8226) were added and incubated at room temperature (RT) for $2 \mathrm{~h}$. The membrane was rinsed and a secondary antibody (1:50000, Abcam, ab6721) was added. They were incubated at RT for $1 \mathrm{~h}$. The bands were detected using an enhanced chemiluminescence kit (Perkin-Elmer, Inc). They were quantified with Imagequant LAS4000 (GE Healthcare, Japan).

\section{Statistical Analysis}

SPSS 20.0 software was used to analyze the data. The differences among groups were tested by Student's $t$-test or one-way ANOVA. The correlation of the two genes was examined by Spearman correlation test. $\mathrm{P}<0.05$ was considered as significant.

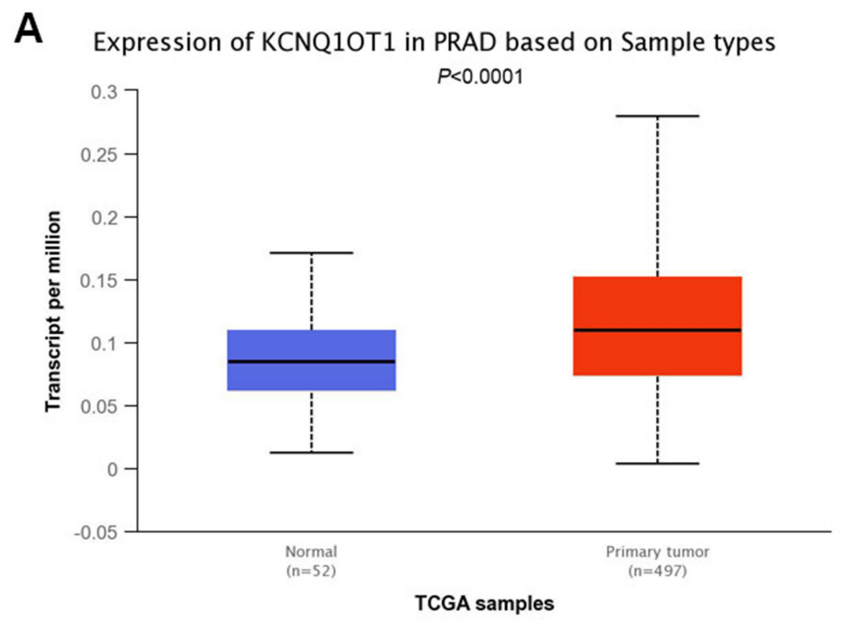

\section{C}

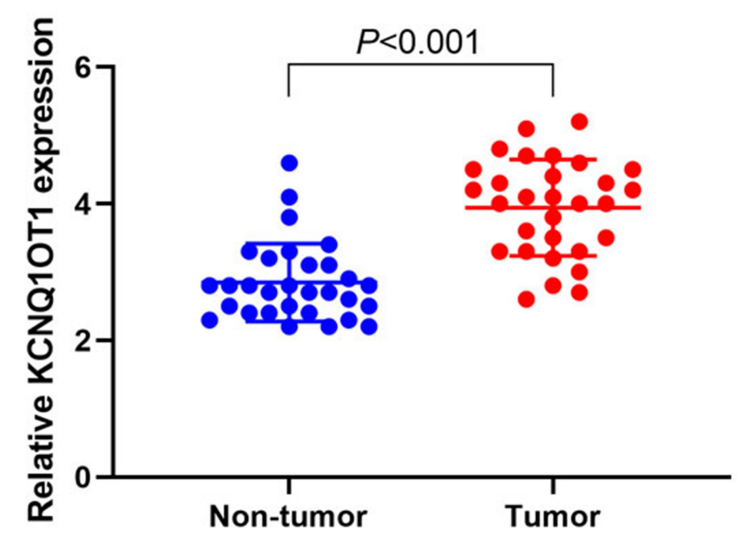

\section{Results}

\section{LncRNA KCNQIOTI Was Upregulated} in PCa Tissues and Cells

UALCAN online analysis of PCa-related data in TCGA database showed that the KCNQ1OT1 expression in $\mathrm{PCa}$ tissues was higher than that in paracancerous tissues (Figure 1A). ${ }^{29}$ The expression exhibited an upward trend with the increase in Gleason score (Figure 1B). RT-PCR results indicated that the KCNQ1OT1 expression in tumor was higher than that in paracancerous tissues (Figure 1C). The KCNQ1OT1 expression in DU145 and LNCaP cells were higher than that in normal RWPE-1 cells (Figure 1D).

\section{Downregulating KCNQIOTI Expression in PCa Cells Inhibited Cell Proliferation, Invasion, and Metastasis}

SiRNA was used to downregulate the KCNQ1OT1 expression in DU145 and LNCaP cells and observe cell

B Expression of KCNQ1OT1 in PRAD based on patient's gleason score

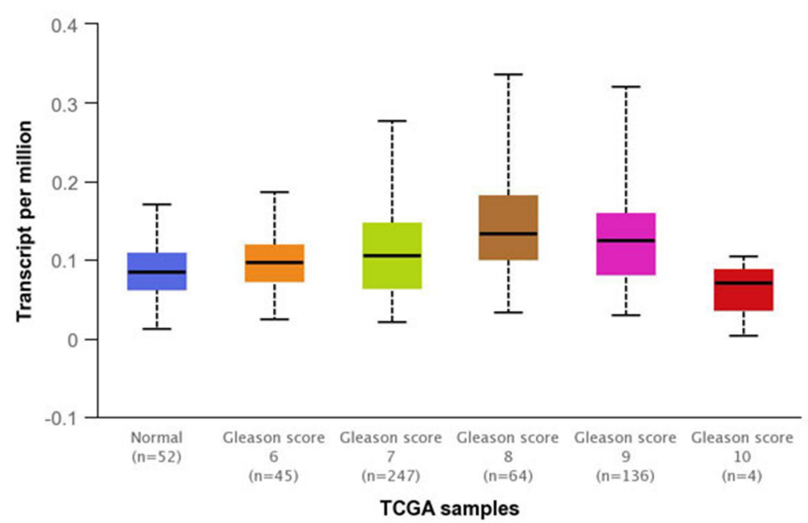

D

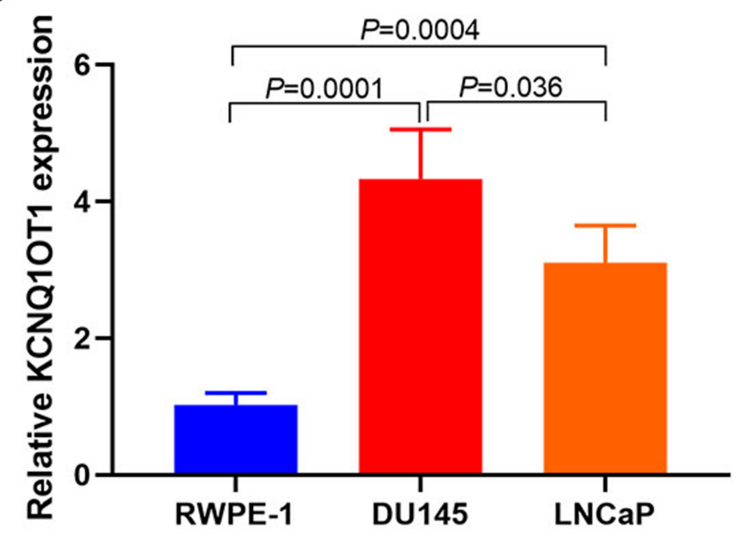

Figure I KCNQIOTI expression. (A) UALCAN analysis of KCNQIOTI expression in TCGA database; (B) UALCAN analysis of KCNQIOTI expression with different Gleason score; (C) RT-PCR results of KCNQIOTI expression in tumor and paracancerous tissues; (D) RT-PCR results of KCNQIOTI expression in DUI45, LNCaP and RWPE-I cells. 
proliferation, invasion, and metastasis. The results showed that the downregulation of KCNQ1OT1 expression (Figure 2A and B) inhibited cell proliferation (Figure 2C and D). Matrigel invasion and Transwell migration results revealed that the invasion and metastasis decreased significantly after downregulating KCNQ1OT1 (Figure 2E and F).

\section{KCNQIOTI Bound with miR-2II-5 and Promoted CHI3LI Expression as ceRNA} The Encyclopedia of RNA Interactomes (ENCORI) ${ }^{30}$ predicted a binding site between KCNQ1OT1 and miR211-5p and between miR-211-5p and CHI3L1 3'-UTR (Figure 3A). Luciferase reporter gene analysis results indicated that KCNQ1OT1 and miR-211-5p (Figure 3B), miR-211-5p, and CHI3L1 3'-UTR (Figure 3C) had targeted regulatory effects. RT-PCR results also indicated that miR-211-5p expression could be regulated by changing KCNQ1OT1 expression in DU145 (Figure 3D) and LNCaP (Figure 3E) cells. The results showed that YKL40 expression could be affected by changing KCNQ1OT1 and miR-211-5p expression levels in DU145 and LNCaP cells (Figure $3 \mathrm{~F}$ and G). As a part of RNA induced silencing complex (RISC), miRNA exists in the cytoplasm. Ago2 also exists in RISC and participates in miRNA-mediated gene silencing. In this study, anti SNRNP70 antibody was used as a positive control, and Ago2 antibody was used to conduct RIP test and analyze whether KCNQ1OT1 and miR-211-5p were present in RISC. Compared with the control (IgG), Ago2 antibody could enrich KCNQ1OT1 and miR-211-5p (Figure $3 \mathrm{H}$ and $\mathrm{I}$ ). These results suggested that KCNQ1OT1 regulated cell proliferation through ceRNA.

\section{Upregulation of miR-2 I I-5 Expression Inhibited the Invasion, Proliferation, and Migration of PCa Cells}

miR-211-5p mimics were transfected into DU145 and LNCaP cells (Figure 4A and B) to observe the changes in cell proliferation, invasion, and metastasis. CCK-8 results indicated that DU145 and $\mathrm{LNCaP}$ proliferation significantly decreased after the transfection of miR-211$5 \mathrm{p}$ mimics (Figure $4 \mathrm{C}$ and $\mathrm{D}, \mathrm{P}<0.01$ ). Matrigel invasion and Transwell migration results indicated that the invasion and metastasis decreased significantly after the transfection of miR-211-5p mimics (Figure 4E and F).

\section{Downregulation of $\mathrm{CHI} 3 \mathrm{LI}$ Expression}

Promoted Proliferation, Invasion, and

\section{Metastasis of PCa Cells}

siRNA was used to downregulate the CHI3L1 expression in DU145 and LNCaP cells and observe cell proliferation, invasion, and metastasis (Figure 5A and B). The results showed that the downregulation of $\mathrm{CHI} 3 \mathrm{~L} 1$ expression inhibited cell proliferation (Figure 5C and D). Matrigel invasion and Transwell migration results demonstrated that the invasion and metastasis decreased significantly after downregulating CHI3L1 (Figure 5E and F).

\section{LncRNA KCNQIOTI/miR-2II-5p/ $\mathrm{CHI}$ LI Signal Axis Exists in $\mathrm{PCa}$}

Immunohistochemical analysis showed that YKL-40 was highly expressed in PCa tissues but lowly expressed in paracancerous tissues (Figure 6A). RT-PCR results illustrated that the miR-211-5p expression was low in tumor tissues and high in paracancerous tissues (Figure 6B). CHI3L1 mRNA expression was high in tumor tissues and low in paracancerous tissues (Figure 6C). A negative correlation was found between KCNQ1OT1 and miR-211$5 p$ (Figure 6D) and between miR-211-5p expression and CHI3L1 (Figure 6E).

\section{Discussion}

LncRNAs were widely reported to be related to various human malignant tumors. They also play a role in pathological processes by regulating gene expression. LncRNAs could be generally used as ceRNAs to bind to microRNAs specifically. CeRNA is a group of different RNAs that compete with mRNA for the same pool of miRNA. They could bind miRNAs via miRNA response elements, acting as "sponge transcripts" by reducing the pool of miRNAs available to downregulate the translation of mRNAs. LncRNAs are also involved in the occurrence and development of PCa. ${ }^{31}$ KCNQ1OT1 is a newly discovered IncRNA. Several studies have shown that KCNQ1OT is associated with breast cancer, non-small cell lung cancer (NSCLC), and bladder cancer. ${ }^{32-34}$ KCNQ1OT1 expression was significantly upregulated in NSCLC and positively correlated with its poor prognosis. ${ }^{32}$ KCNQ1OT1 expression was also upregulated in breast cancer tissues and cells, and it promoted tumor progression through miR-145/CCNE2. ${ }^{33}$ In bladder cancer, KCNQ1OT1 promoted cell proliferation and migration by regulating the 
A

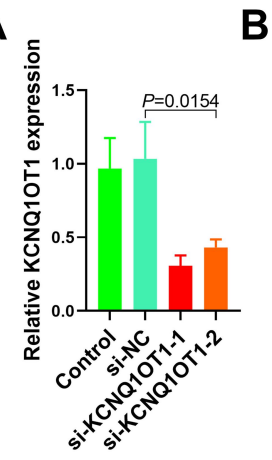

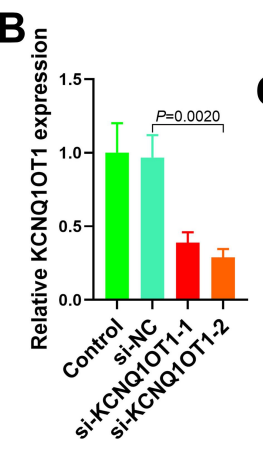
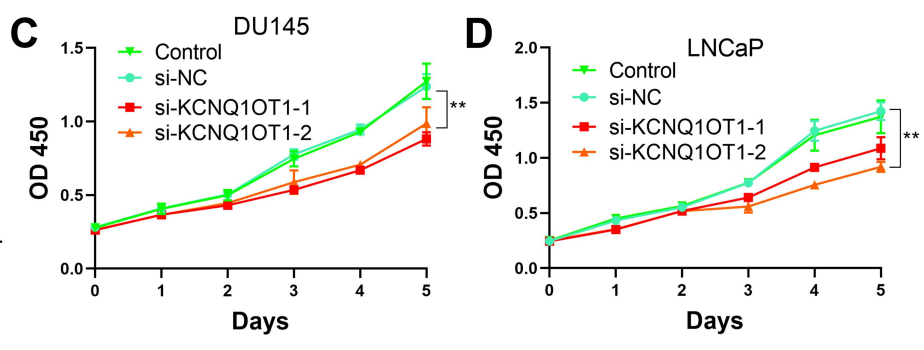

E

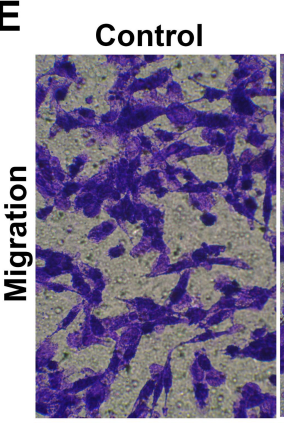

si-NC

si-KCNQ10T1-1 si-KCNQ10T1-2
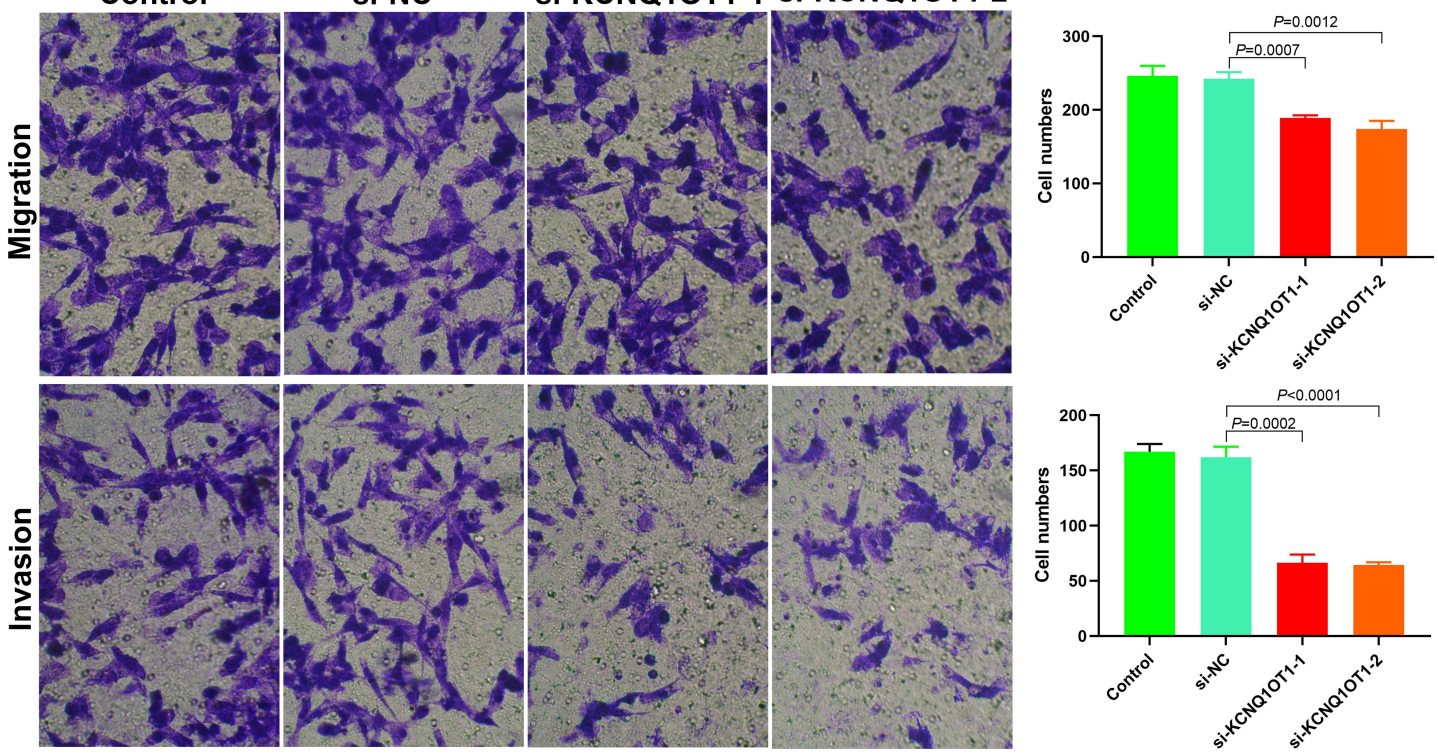

$\mathbf{F}$

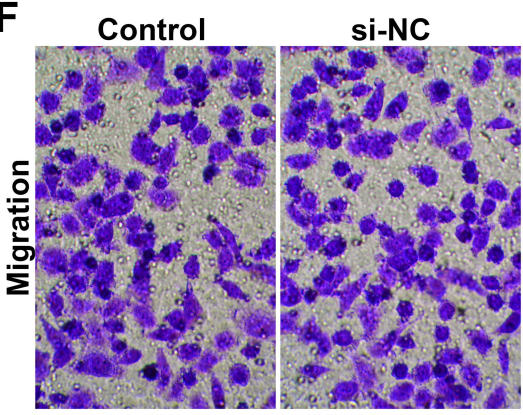

si-KCNQ1OT1-1 si-KCNQ10T1-2
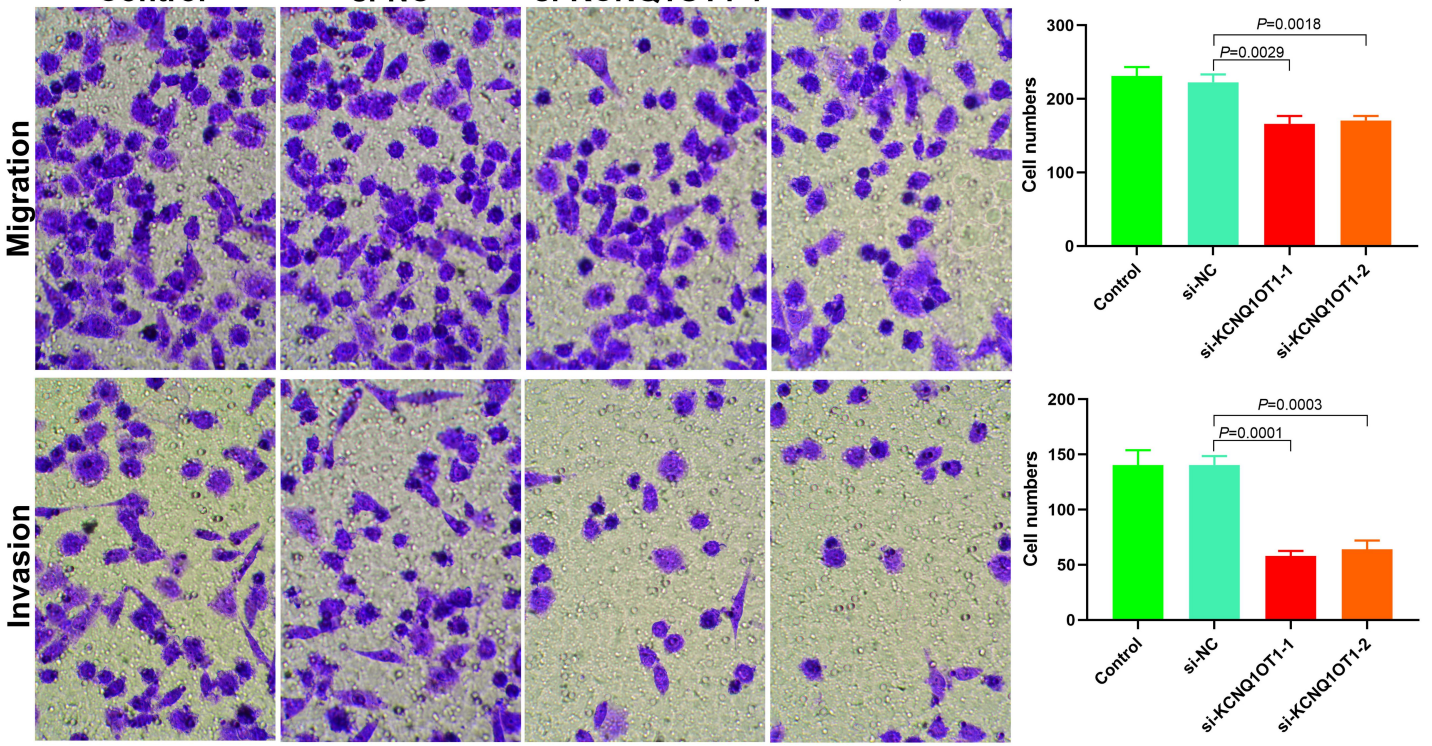

Figure 2 Effects of KCNQIOTI on proliferation, invasion and metastasis of prostate cancer cells. (A) The expression level of KCNQIOTI after si-RNA being transfected into DUI 45 cells; (B) The expression level of KCNQIOTI after si-RNA being transfected into LNCaP cells; (C) The DUI 45 cell proliferation was decreased after down regulation of the KCNQIOTI expression (**P<0.0I); (D) The LNCaP cell proliferation was decreased after down regulation of the KCNQIOTI expression (**P<0.01); (E) Cell migration and invasion decreased after down regulation of the KCNQIOTI expression in DUI 45 cells; (F) Cell migration and invasion decreased after down regulation of the KCNQIOTI expression in LNCaP cells. 
A

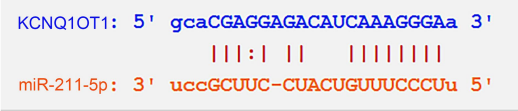

KCNQ10T1: 5 ' gacuaAAUGAUAACAUGGAAAGGGAC 3 '

|| ||| || |11111|

miR-211-5p: $3^{\prime}$ uccgcUUCCUACUG----UUUCCCUu 5 '

KCNQ10T1: 5' agaaacuucCUGA-AAAGGGAa $3^{\prime}$

|I| |||||||

miR-211-5p: $3^{\prime}$ uccgcuuccuACUGUUUCCCUu 5

CHI3L1 3' -UTR : 5 ' uCCCCAAGCCUGG-CAAGGGa 3'

| || |1: ||||||

miR-211-5p: $3^{\prime}$ ucCGCUUCCUACUGUUUCCCUu 5
B

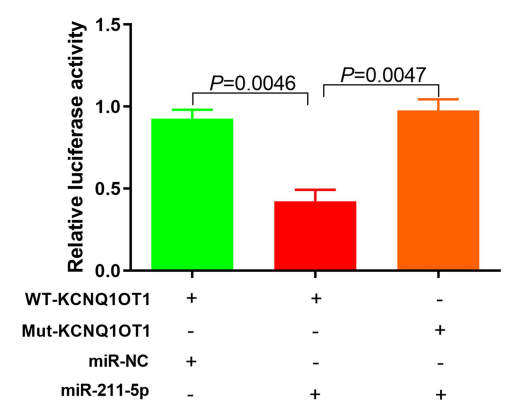

C

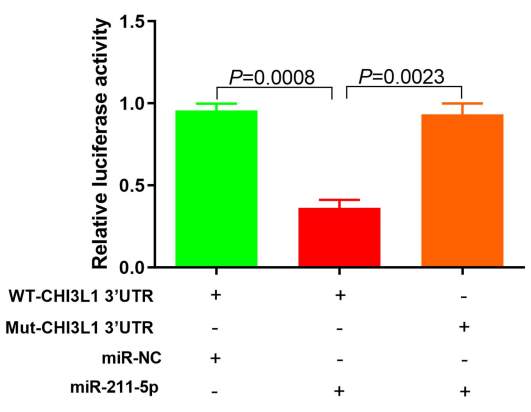

D

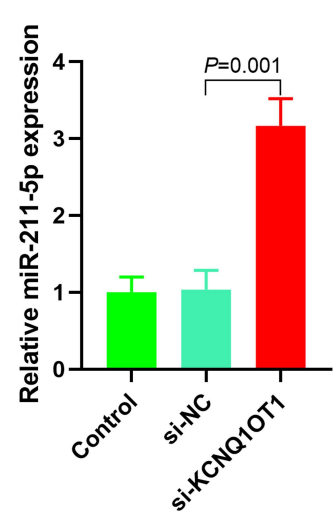

E

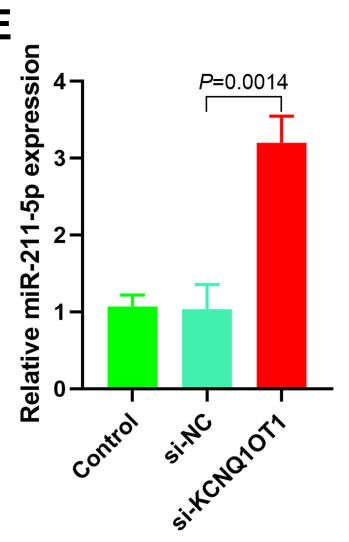

$\mathbf{F}$

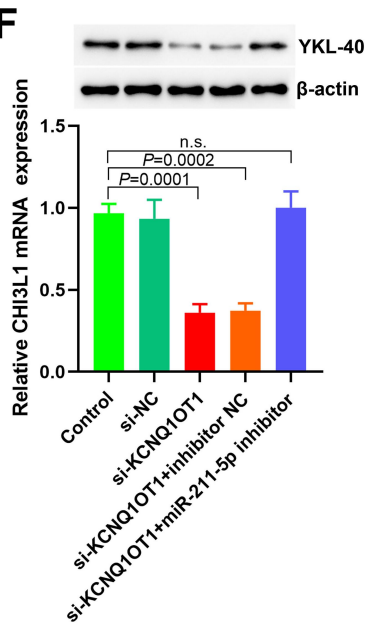

G

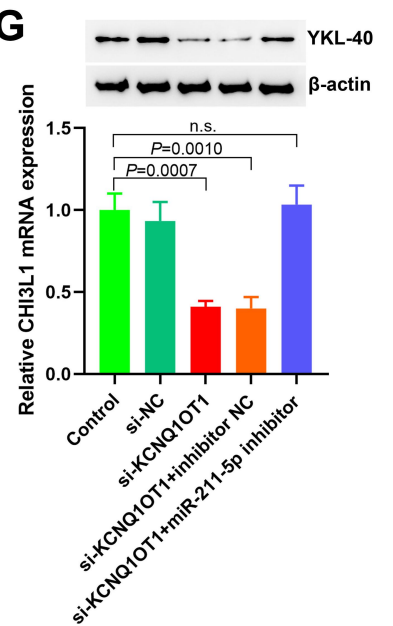

H

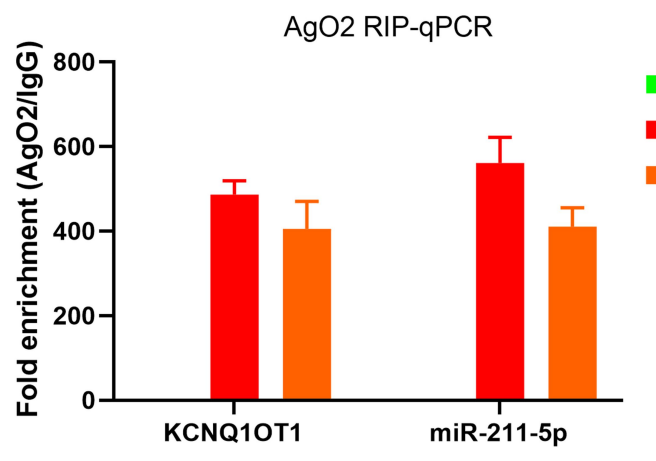

I ত

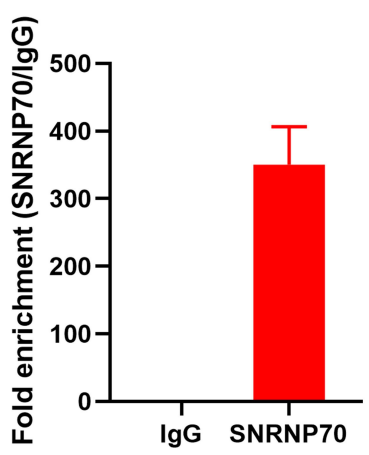

Figure 3 KCNQIOTI functions as a ceRNA and sponges miR-2II-5p. (A) The binding sites of KCNQIOTI with miR-2II-5p and miR-2II-5P with CHI3LI 3'-UTR were predicted by ENCORI analysis, and the corresponding wild-type and mutant luciferase reporter gene plasmids were constructed; (B) The targeting effect of KCNQIOTI and miR-2II-5p was analyzed; (C) The targeting effect of CHI3LI 3'-UTR and miR-2II-5p was analyzed; (D) The effect of down regulating KCNQIOTI on miR-2II-5p expression in DUI45 cells detected by RT-PCR; (E) The effect of overexpressed KCNQIOTI on miR-2II-5p expression in LNCaP cells detected by RT-PCR; (F) The effect of changing KCNQIOTI and miR-2II-5p levels on YKL-40 expression in DUI45 cells detected by RT-PCR and Western blot; (G) The effect of changing KCNQIOTI and miR-2 I I-5p levels on YKL-40 expression in LNCaP cells detected by RT-PCR and Western blot; (H) The enrichment of KCNQIOTI and miR-2I I-5p by Ago2 antibody analyzed by RIP assay; (I) SNRNP70 antibody was used as positive control in RIP assay.

Abbreviation: n.s., no significant difference.

miR-145-5p/PCBP2 signal axis. $^{34}$ The present study revealed that the KCNQ1OT1 expression in PCa tissues was higher than that in paracancerous tissues. The KCNQ1OT1 expression in PCa cells was also higher than that in RWPE1 cells. Inhibition of KCNQ1OT1 expression in $\mathrm{PCa}$ cells could inhibit cell proliferation, invasion, and metastasis. These results indicated that KCNQ1OT1 may play the role of oncogene in PCa.

miRNAs mainly participate in the post-transcriptional regulation of target genes. They participate in the regulation of many biological processes, and they are important in the treatment and prognosis of tumors. One study 


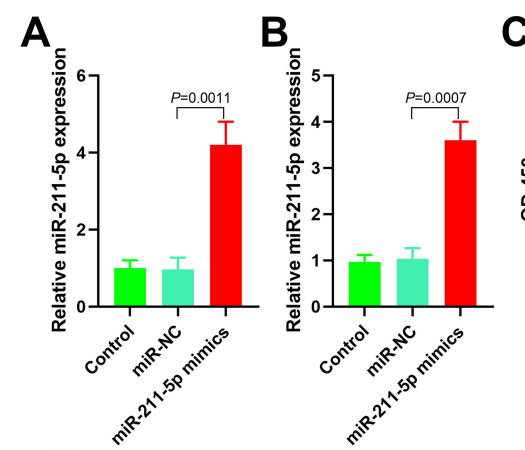

$\mathbf{E}$
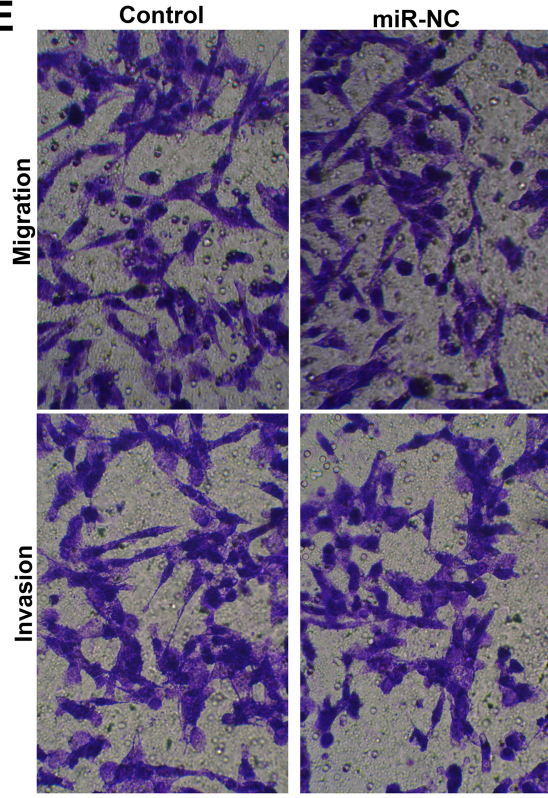

$\mathbf{F}$
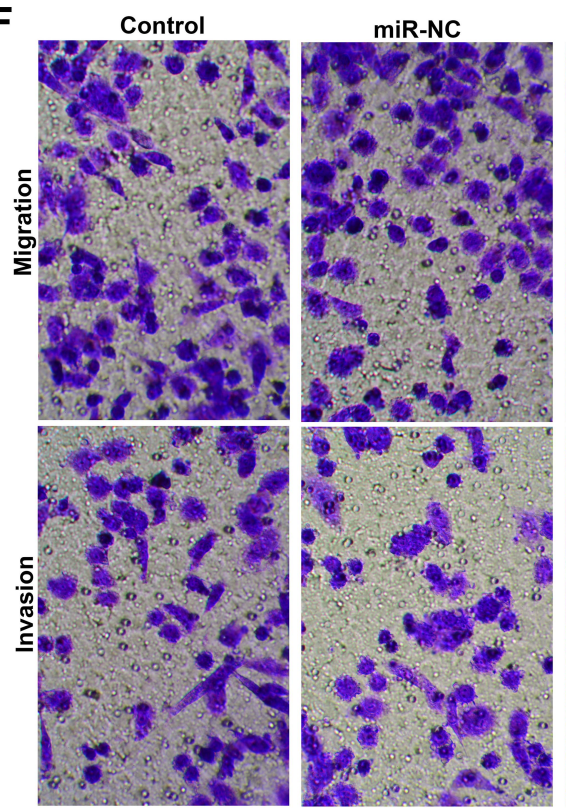

C

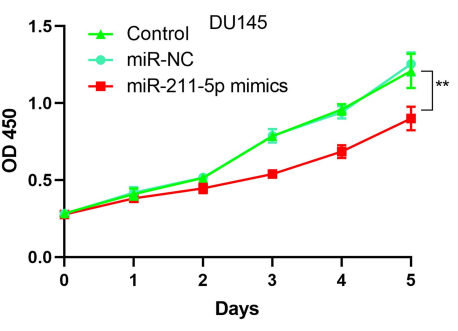

D

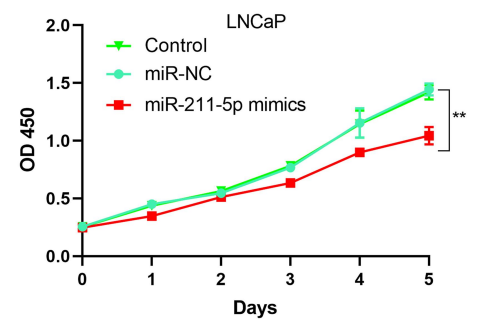

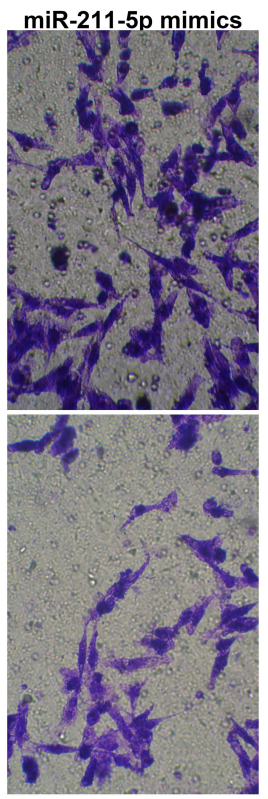
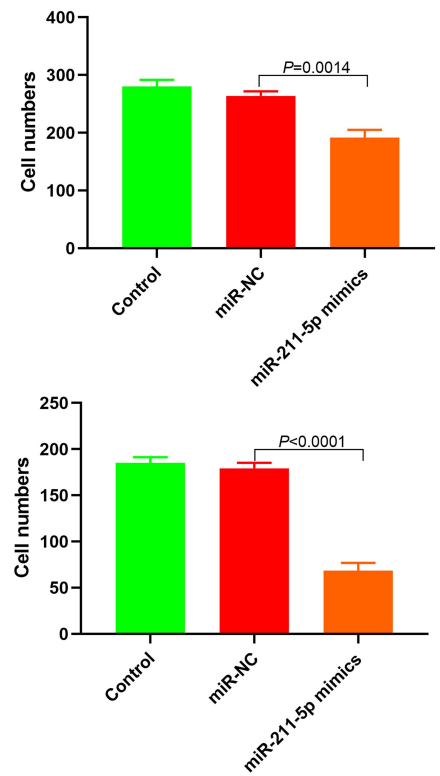

miR-211-5p mimics
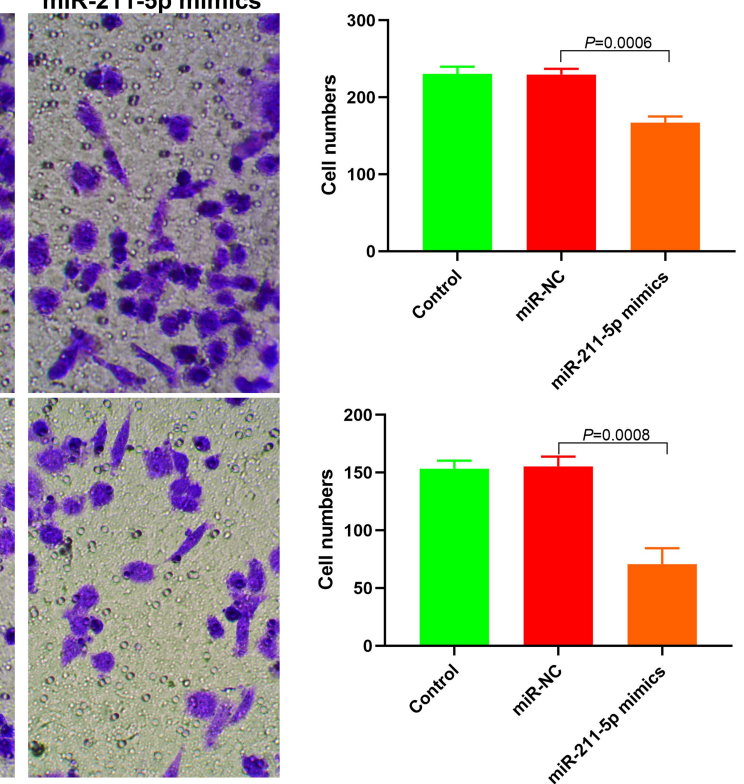

Figure 4 Effect of miR-2 I I-5 on proliferation, invasion and metastasis of prostate cancer cells. (A) The expression level of miR-2 I I-5 after transfection of miR-2 I I-5 mimics into DUI45 cells; (B) The expression level of miR-2II-5 after transfection of miR-2II-5 mimics into LNCaP cells; (C) Cell proliferation decreased after transfection of miR2II-5 mimics into DUI45 cells (**P<0.0I); (D) Cell proliferation decreased after transfection of miR-2II-5 mimics into LNCaP cells ( $* * P<0.0$ I); (E) Matrigel invasion and transwell migration assays showed decreased cell migration and invasion after transfection of miR-2II-5 mimics into DUI45 cells; (F) Matrigel invasion and transwell migration assays showed decreased cell migration and invasion after transfection of miR-2 I I-5 mimics into LNCaP cells. 

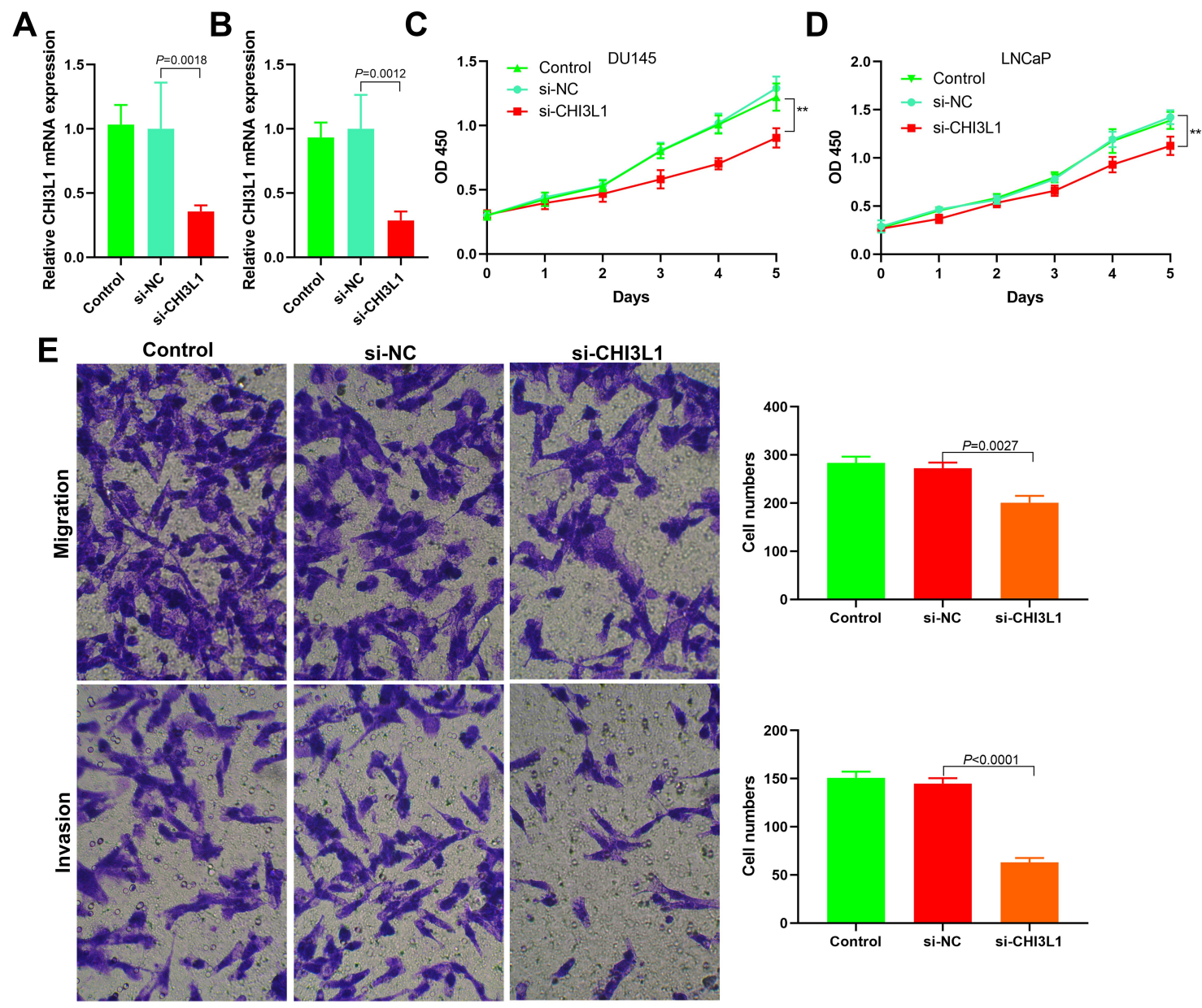

F
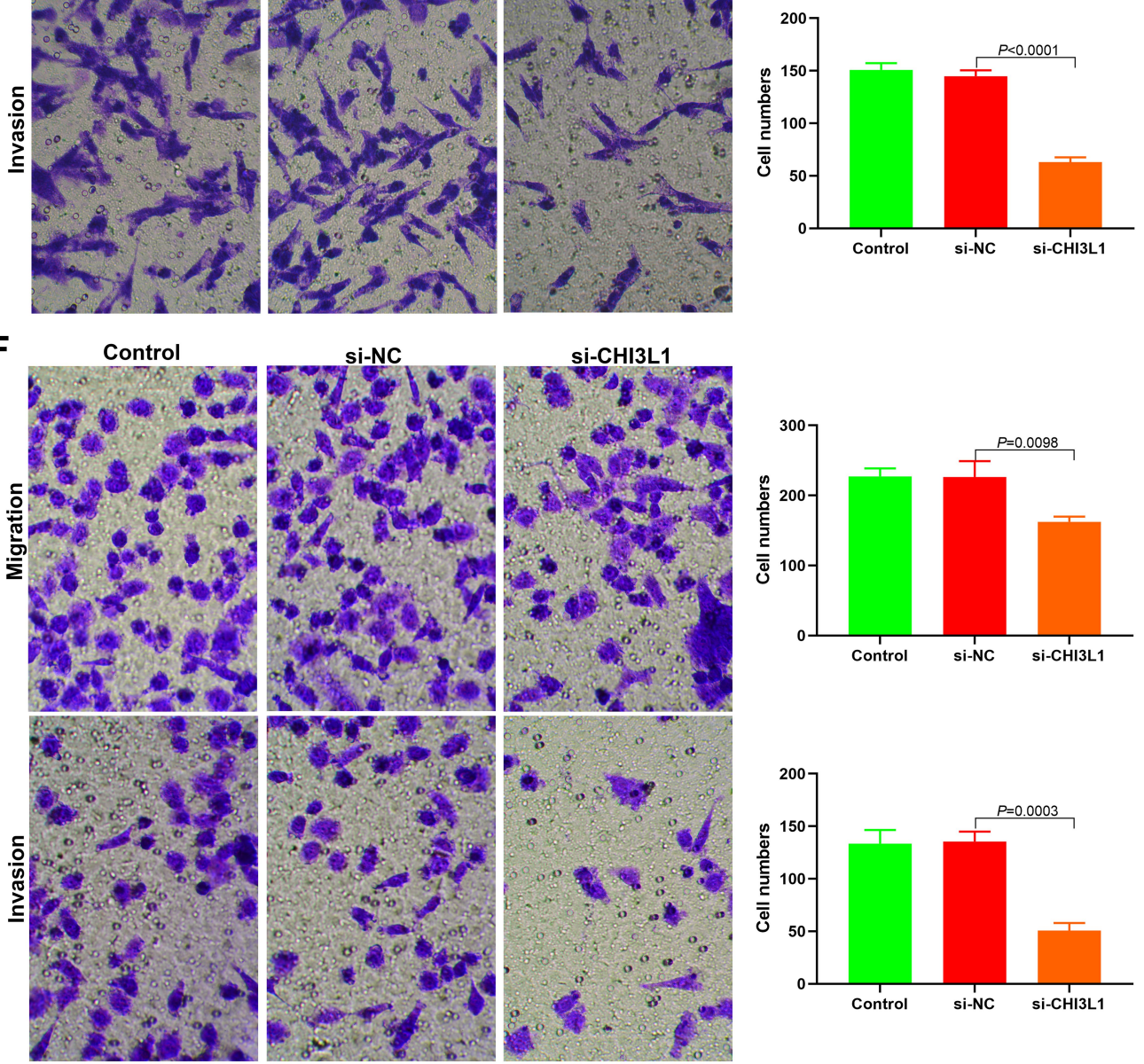

Figure 5 Effect of $\mathrm{CHI} 3 \mathrm{LI}$ expression on proliferation, invasion and metastasis of prostate cancer cells. (A) The expression level of $\mathrm{CHI} 3 \mathrm{LI}$ after transfection of $\mathrm{CHI} 3 \mathrm{LI}$ siRNA into DUI45 cells; (B) The expression level of CHI3LI after transfection of CHI3LI siRNA into LNCaP cells; (C) Cell proliferation decreased after transfection of CHI3LI siRNA into DUI45 cells ( ${ }^{* * P<0.0 I) ; ~(D) ~ C e l l ~ p r o l i f e r a t i o n ~ d e c r e a s e d ~ a f t e r ~ t r a n s f e c t i o n ~ o f ~ C H I 3 L I ~ s i R N A ~ i n t o ~ L N C a P ~ c e l l s ~(* * P<0.0 I) ; ~(E) ~ M a t r i g e l ~ i n v a s i o n ~ a n d ~}$ transwell migration assays showed decreased cell migration and invasion after transfection of CHI3LI siRNA into DUI45 cells; (F) Matrigel invasion and transwell migration assays showed decreased cell migration and invasion after transfection of CHI3LI siRNA into LNCaP cells. 
A

Tumor

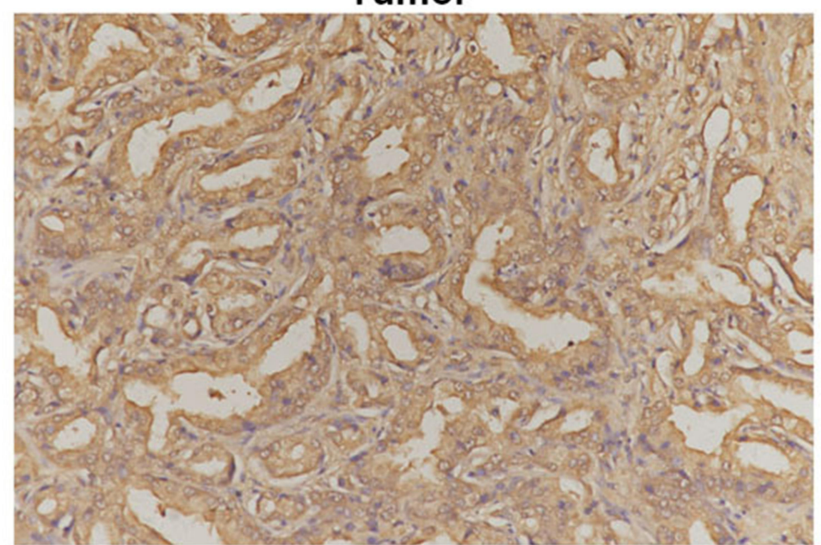

B

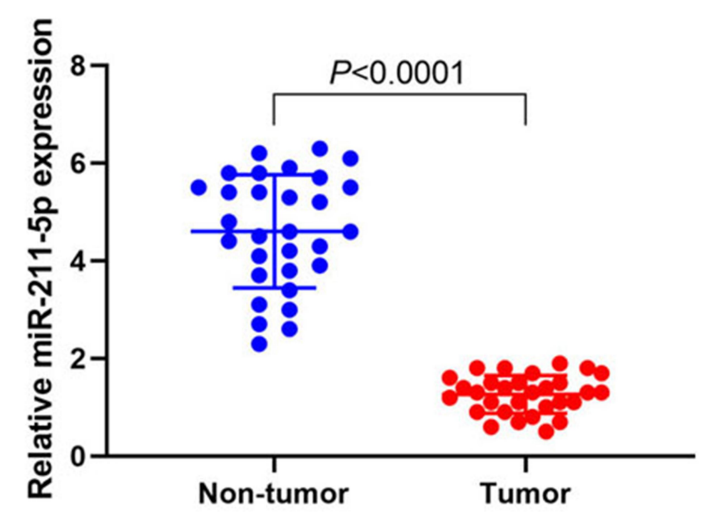

D

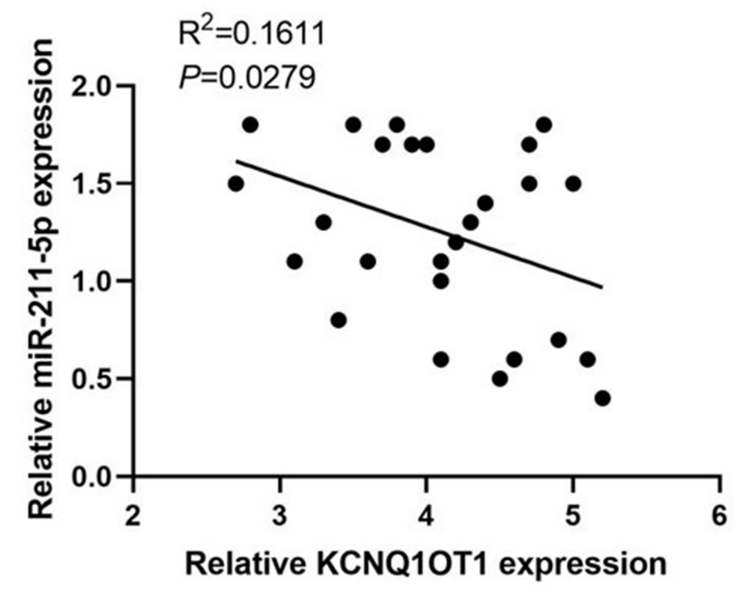

Non-tumor

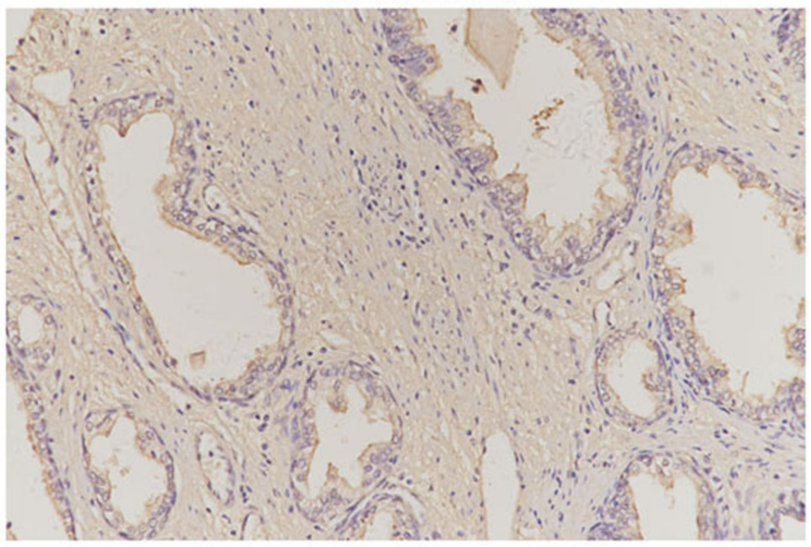

C

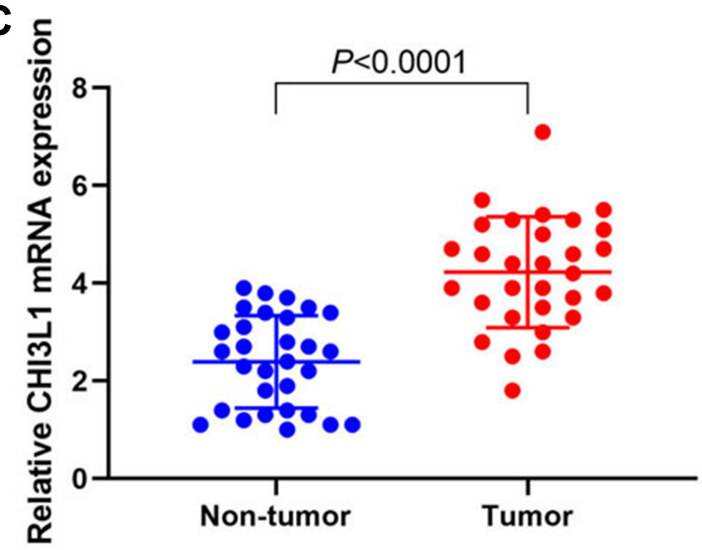

$\mathbf{E}$

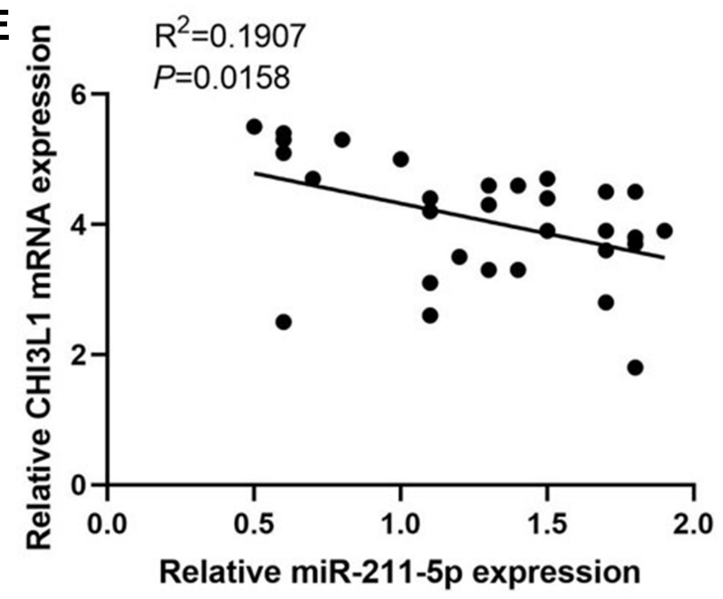

Figure 6 IncRNA KCNQIOTI/miR-2II-5p/CHI3LI signal axis exists in prostate cancer. (A) Immunohistochemical results of YKL-40 expression; (B) RT-PCR results of miR-2II-5p expression; (C) RT-PCR results of CHI3LI mRNA expression; (D) Correlation analysis of KCNQIOTI and miR-2II-5p expression levels; (E) Correlation analysis of miR-2II-5p and CHI3LI mRNA expression levels.

reported the role of miRNAs in the occurrence and development of $\mathrm{PCa}^{35}$ To the knowledge of the authors, the function of miR-211-5p has not been reported in PCa. Bioinformatic prediction showed that KCNQ1OT1 and miR-211-5p had targeted binding sites. KCNQ1OT1 could target binding with miR-211-5p. The KCNQ1OT1 and miR-211-5p expression levels were negatively correlated in PCa. In breast cancer, miR-211-5p could promote apoptosis by inhibiting SIRT1 expression. ${ }^{36}$ MiR-211-5p could also inhibit the metastasis of renal cell carcinoma by targeting SNAI1. ${ }^{27}$ In addition, miR211-5p played the role of tumor suppressor gene in

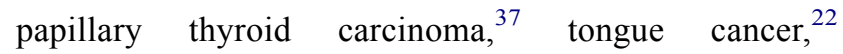
melanoma, ${ }^{38}$ cervical cancer $^{39}$ and primary liver 
cancer. $^{28}$ The present study revealed that the miR-211-5p expression in $\mathrm{PCa}$ tissues was lower than that in paracancerous tissues or normal prostate epithelial cells. miR-211-5p mimic transfection could inhibit cell invasion, proliferation, and metastasis. Therefore, miR-211$5 \mathrm{p}$ also played the role of tumor suppressor gene in $\mathrm{PCa}$.

YKL-40, a $40 \mathrm{kDa}$ protein, is secreted by human osteosarcoma cell line MG63. In terms of structure, it is related to mammalian chitinase-like proteins, but it lacks specific enzyme activity. Increased YKL-40 levels have been reported in various diseases, such as liver cirrhosis, inflammatory bowel disease, rheumatoid arthritis, bacterial septicemia, and malignant tumor. ${ }^{40-44}$ YKL-40 may be related to tumor cell differentiation and proliferation, apoptotic inhibition, angiogenesis, and other processes, and it could start extracellular matrix remodeling. ${ }^{4}$ Elevated serum YKL-40 levels were associated with the invasion, proliferation, and metastasis of various cancer cells, including $\mathrm{PCa}^{5-11}$ A previous study showed that YKL-40 promoted the invasion and metastasis of $\mathrm{PCa}$ cells by regulating the EMT. The present study found that YKL-40 expression was increased in PCa. Bioinformatics showed that miR211-5p could target CHI3L1 3'-UTR. The results of luciferase reporter gene analysis and RIP experiments also confirmed that they could target bind, and miR211-5p could inhibit CHI3L1 expression. YKL-40 mRNA and miR-211-5p expression levels were negatively correlated. Downregulating the KCNQ1OT1 expression or upregulating the miR-211-5p expression in PCa cells could inhibit YKL-40 expression and inhibit cell proliferation, invasion, and metastasis. These findings suggested that LncRNA KCNQ1OT1, as a ceRNA, promoted the proliferation, invasion, and metastasis of $\mathrm{PCa}$ by regulating the miR-211-5p/CHI3L1 signal axis.

\section{Conclusions}

In summary, this study showed that KCNQ1OT1 was upregulated in $\mathrm{PCa}$ and it acted as a molecular sponge to antagonize the negative regulation of miR-211-5p on YKL-40, thus promoting PCa occurrence. The lncRNA KCNQ1OT1/miR-211-5p/CHI3L1 signal axis may be a new therapeutic target for $\mathrm{PCa}$. The upregulation of miR-211-5p or the downregulation of KCNQ1OT1 and CHI3L1 may be a therapeutic method to inhibit the malignant growth of PCa cells. A new signal pathway that mediated the invasion and metastasis of $\mathrm{PCa}$ was revealed, and it may provide a new target for PCa diagnosis and treatment.

\section{Data Sharing Statement}

The data used to support the findings of this study are available from the corresponding author upon request.

\section{Author Contributions}

All authors made a significant contribution to the work reported, whether that is in the conception, study design, execution, acquisition of data, analysis and interpretation, or in all these areas; took part in drafting, revising or critically reviewing the article; gave final approval of the version to be published; have agreed on the journal to which the article has been submitted; and agree to be accountable for all aspects of the work.

\section{Disclosure}

The authors declare no conflicts of interest.

\section{References}

1. Grozescu T, Popa F. Prostate cancer between prognosis and adequate/ proper therapy. J Med Life. 2017;10(1):5-12.

2. Sebesta EM, Anderson CB. The surgical management of prostate cancer. Semin Oncol. 2017;44(5):347-357. doi:10.1053/j.seminoncol. 2018.01.003

3. Mansinho A, Macedo D, Fernandes I, Costa L. Castration-resistant prostate cancer: mechanisms, targets and treatment. Adv Exp Med Biol. 2018;1096:117-133.

4. Johansen JS, Jensen BV, Roslind A, Nielsen D, Price PA. Serum YKL-40, a new prognostic biomarker in cancer patients? Cancer Epidemiol Biomarkers Prev. 2006;15(2):194-202. doi:10.1158/10559965.EPI-05-0011

5. Kim SH, Das K, Noreen S, Coffman F, Hameed M. Prognostic implications of immunohistochemically detected YKL-40 expression in breast cancer. World J Surg Oncol. 2007;5(1):17. doi:10.1186/ 1477-7819-5-17

6. Cintin C, Johansen JS, Christensen IJ, Price PA, Sørensen S, Nielsen HJ. High serum YKL-40 level after surgery for colorectal carcinoma is related to short survival. Cancer. 2002;95(2):267-274. doi:10.1002/cncr.10644

7. Høgdall EV, Ringsholt M, Høgdall CK, et al. YKL-40 tissue expression and plasma levels in patients with ovarian cancer. BMC Cancer. 2009;9(1):8. doi:10.1186/1471-2407-9-8

8. Johansen JS, Drivsholm L, Price PA, Christensen IJ. High serum YKL-40 level in patients with small cell lung cancer is related to early death. Lung Cancer. 2004;46(3):333-340. doi:10.1016/j. lungcan.2004.05.010

9. Özdemir E, Çiçek T, Kaya MO. Association of serum YKL-40 level with tumor burden and metastatic stage of prostate cancer. Urol J. 2012;9(3):568-573.

10. Coskun U, Yamac D, Gulbahar O, Sancak B, Karaman N, Ozkan S. Locally advanced breast carcinoma treated with neoadjuvant chemotherapy: are the changes in serum levels of YKL-40, MMP-2 and MMP-9 correlated with tumor response?. Neoplasma. 2007;54 (4):348-352 
11. Hao H, Wang L, Chen $\mathrm{H}$, et al. YKL-40 promotes the migration and invasion of prostate cancer cells by regulating epithelial mesenchymal transition. Am J Transl Res. 2017;9(8):3749-3757.

12. Paraskevopoulou MD, Hatzigeorgiou AG. Analyzing MiRNA-LncRNA interactions. Methods Mol Biol. 2016;1402:271286. doi:10.1007/978-1-4939-3378-5_21

13. Ferrè $F$, Colantoni A, Helmer-Citterich $M$. Revealing protein-lncRNA interaction. Brief Bioinform. 2016;17(1):106-116. doi:10.1093/bib/bbv031

14. Martens-Uzunova ES, Böttcher R, Croce CM, Jenster G, Visakorpi T, Calin GA. Long noncoding RNA in prostate, bladder, and kidney cancer. Eur Urol. 2014;65(6):1140-1151. doi:10.1016/j.eururo.20 13.12.003

15. Zhang Y, Tang L. The application of lncRNAs in cancer treatment and diagnosis. Recent Pat Anticancer Drug Discov. 2018;13 (3):292-301. doi:10.2174/1574892813666180226121819

16. Peng WX, Koirala P, Mo YY. LncRNA-mediated regulation of cell signaling in cancer. Oncogene. 2017;36(41):5661-5667. doi:10.1038/ onc. 2017.184

17. Chen Z, Chen X, Xie R, et al. DANCR promotes metastasis and proliferation in bladder cancer cells by enhancing IL-11-STAT3 signaling and CCND1 expression. Mol Ther. 2019;27(2):326-341. doi:10.1016/j.ymthe.2018.12.015

18. Gu P, Chen X, Xie R, et al. A novel AR translational regulator lncRNA LBCS inhibits castration resistance of prostate cancer. Mol Cancer. 2019;18(1):109. doi:10.1186/s12943-019-1037-8

19. Prensner JR, Iyer MK, Sahu A, et al. The long noncoding RNA SChLAP1 promotes aggressive prostate cancer and antagonizes the SWI/SNF complex. Nat Genet. 2013;45(11):1392-1398. doi:10.1038/ ng.2771

20. Zhang A, Zhao JC, Kim J, et al. LncRNA HOTAIR enhances the androgen-receptor-mediated transcriptional program and drives castration-resistant prostate cancer. Cell Rep. 2015;13(1):209-221. doi:10.1016/j.celrep.2015.08.069

21. Yu Y, Chen Y, Zhang X, et al. Knockdown of lncRNA KCNQ1OT1 suppresses the adipogenic and osteogenic differentiation of tendon stem cell via downregulating miR-138 target genes PPAR $\gamma$ and RUNX2. Cell Cycle. 2018;17(19-20):2374-2385. doi:10.1080/ 15384101.2018.1534510

22. Zhang S, Ma H, Zhang D, et al. LncRNA KCNQ1OT1 regulates proliferation and cisplatin resistance in tongue cancer via miR-211-5p mediated Ezrin/Fak/Src signaling. Cell Death Dis. 2018;9(7):742. doi:10.1038/s41419-018-0793-5

23. Guo B, Zhang Q, Wang H, et al. KCNQ1OT1 promotes melanoma growth and metastasis. Aging (Albany NY). 2018;10(4):632-644. doi:10.18632/aging.101418

24. Li Y, Li C, Li D, et al. IncRNA KCNQ1OT1 enhances the chemoresistance of oxaliplatin in colon cancer by targeting the miR-34a/ ATG4B pathway. Onco Targets Ther. 2019;12:2649-2660. doi:10.2147/OTT.S188054

25. Cheng P, Lu P, Guan J, et al. LncRNA KCNQ1OT1 controls cell proliferation, differentiation and apoptosis by sponging miR-326 to regulate c-Myc expression in acute myeloid leukemia. Neoplasma. 2020;67(2):238-248. doi:10.4149/neo 2018 181215N972

26. Chen QH, Li B, Liu DG, et al. LncRNA KCNQ1OT1 sponges miR-15a to promote immune evasion and malignant progression of prostate cancer via up-regulating PD-L1. Cancer Cell Int. 2020;20 (1):394. doi:10.1186/s12935-020-01481-8

27. Wang $\mathrm{K}$, Jin $\mathrm{W}$, Jin $\mathrm{P}$, et al. miR-211-5p suppresses metastatic behavior by targeting SNAI1 in renal cancer. Mol Cancer Res. 2017;15(4):448-456. doi:10.1158/1541-7786.MCR-16-0288

28. Jiang G, Wen L, Deng W, Jian Z, Zheng H. Regulatory role of miR-211-5p in hepatocellular carcinoma metastasis by targeting ZEB2. Biomed Pharmacother. 2017;90:806-812. doi:10.1016/j. biopha.2017.03.081
29. Chandrashekar DS, Bashel B, Balasubramanya SAH, et al. UALCAN: a portal for facilitating tumor subgroup gene expression and survival analyses. Neoplasia. 2017;19(8):649-658. doi:10.1016/j. neo.2017.05.002

30. Li JH, Liu S, Zhou H, Qu LH, Yang JH. starBase v2.0: decoding miRNA-ceRNA, miRNA-ncRNA and protein-RNA interaction networks from large-scale CLIP-Seq data. Nucleic Acids Res. 2014;42 (Databaseissue):D92-D97. doi:10.1093/nar/gkt1248

31. Gu P, Chen X, Xie R, et al. IncRNA HOXD-AS1 regulates proliferation and chemo-resistance of castration-resistant prostate cancer via recruiting WDR5. Mol Ther. 2017;25(8):1959-1973. doi:10.1016/j. ymthe.2017.04.016

32. Kang Y, Jia Y, Wang Q, et al. Long noncoding RNA KCNQ1OT1 promotes the progression of non-small cell lung cancer via regulating miR-204-5p/ATG3 axis. Onco Targets Ther. 2019;12:10787-10797. doi:10.2147/OTT.S226044

33. Feng W, Wang $\mathrm{C}$, Liang $\mathrm{C}$, et al. The dysregulated expression of KCNQ1OT1 and Its interaction with downstream factors miR-145/ CCNE2 in breast cancer cells. Cell Physiol Biochem. 2018;49 (2):432-446. doi:10.1159/000492978

34. Wang J, Zhang H, Situ J, Li M, Sun H. KCNQ1OT1 aggravates cell proliferation and migration in bladder cancer through modulating miR-145-5p/PCBP2 axis. Cancer Cell Int. 2019;19(1):325. doi:10.1186/s12935-019-1039-z

35. Kanwal R, Plaga AR, Liu X, Shukla GC, Gupta S. MicroRNAs in prostate cancer: functional role as biomarkers. Cancer Lett. 2017;407:9-20. doi:10.1016/j.canlet.2017.08.011

36. Yarahmadi S, Abdolvahabi Z, Hesari Z, et al. Inhibition of sirtuin 1 deacetylase by miR-211-5p provides a mechanism for the induction of cell death in breast cancer cells. Gene. 2019;711:143939. doi:10.1016/j.gene.2019.06.029

37. Liang M, Jia J, Chen L, et al. LncRNA MCM3AP-AS1 promotes proliferation and invasion through regulating miR-211-5p/SPARC axis in papillary thyroid cancer. Endocrine. 2019;65(2):318-326. doi:10.1007/s12020-019-01939-4

38. Díaz-Martínez M, Benito-Jardón L, Alonso L, Koetz-Ploch L, Hernando E, Teixidó J. miR-204-5p and miR-211-5p contribute to BRAF inhibitor resistance in melanoma. Cancer Res. 2018;78 (4):1017-1030. doi:10.1158/0008-5472.CAN-17-1318

39. Liu S, Wang $\mathrm{H}$, $\mathrm{Mu} \mathrm{J}$, et al. MiRNA-211 triggers an autophagy-dependent apoptosis in cervical cancer cells: regulation of Bcl-2. Naunyn Schmiedebergs Arch Pharmacol. 2020;393 (3):359-370. doi:10.1007/s00210-019-01720-4

40. Rathcke CN, Vestergaard H. YKL-40, a new inflammatory marker with relation to insulin resistance and with a role in endothelial dysfunction and atherosclerosis. Inflamm Res. 2006;55(6):221-227. doi:10.1007/s00011-006-0076-y

41. Johansen JS, Jensen HS, Price PA. A new biochemical marker for joint injury. Analysis of YKL-40 in serum and synovial fluid. $\mathrm{Br}$ $J$ Rheumatol. 1993;32(11):949-955. doi:10.1093/rheumatology/ 32.11 .949

42. Johansen JS, Krabbe KS, Møller K, Pedersen BK. Circulating YKL-40 levels during human endotoxaemia. Clin Exp Immunol. 2005;140(2):343-348. doi:10.1111/j.1365-2249.2005.02763.x

43. Johansen JS. Studies on serum YKL-40 as a biomarker in diseases with inflammation, tissue remodelling, fibroses and cancer. Dan Med Bull. 2006;53(2):172-209.

44. De Ceuninck F, Gaufillier S, Bonnaud A, Sabatini M, Lesur C, Pastoureau P. YKL-40 (cartilage gp-39) induces proliferative events in cultured chondrocytes and synoviocytes and increases glycosaminoglycan synthesis in chondrocytes. Biochem Biophys Res Commun. 2001;285(4):926-931. doi:10.1006/bbrc.2001.5253 


\section{Publish your work in this journal}

OncoTargets and Therapy is an international, peer-reviewed, open access journal focusing on the pathological basis of all cancers, potential targets for therapy and treatment protocols employed to improve the management of cancer patients. The journal also focuses on the impact of management programs and new therapeutic

Submit your manuscript here: https://www.dovepress.com/oncotargets-and-therapy-journa agents and protocols on patient perspectives such as quality of life, adherence and satisfaction. The manuscript management system is completely online and includes a very quick and fair peer-review system, which is all easy to use. Visit http://www.dovepress.com/ testimonials.php to read real quotes from published authors. 